This is a revised personal version of the text of the final journal article, which is made available for scholarly purposes only, in accordance with the journal's author permissions. The full citation is:

G. Chinellato, C. Cavinato, D. Bolzonella, S. Heaven, C.J. Banks, Biohydrogen production from food waste in batch and semi-continuous conditions: Evaluation of a two-phase approach with digestate recirculation for $\mathrm{pH}$ control, International Journal of Hydrogen Energy, Available online 7 March 2013, ISSN 0360-3199, 10.1016/j.jjhydene.2013.01.078.

http://www.sciencedirect.com/science/article/pii/S0360319913001870

doi:: 10.1016/j.ijhydene.2013.01.078

\title{
Biohydrogen production from food waste in batch and semi-continuous conditions: evaluation of a two-phase approach with digestate recirculation for pH control
}

Chinellato G. ${ }^{1}$, Cavinato C. ${ }^{1}{ }^{*}$, Bolzonella D. ${ }^{2,3}$, Heaven S. ${ }^{2}$, Banks C.J. ${ }^{2}$

${ }^{1}$ University Ca' Foscari of Venice, Department of Environmental Sciences, Informatics and Statistics, Calle Larga Santa Marta, Dorsoduro.

${ }^{2}$ Faculty of Civil Engineering and the Environment, University of Southampton, Southampton, SO17 1BJ, UK

${ }^{3}$ Department of Biotechnology, University of Verona, 37134 Verona, Italy

\begin{abstract}
The research investigated the production of Biohythane in a two-phase anaerobic digestion process treating food waste as substrate. Preliminary batch assays were carried out at initial organic loadings of $15,20,25$ and $30 \mathrm{~kg} \mathrm{TVS} \mathrm{m}^{-3}$, in stirred $1.5-1$ reactors at $55^{\circ} \mathrm{C}$. The results showed all hydrogen was produced within the first 24 hours after feeding and the highest load tested gave the maximum hydrogen production $\left(0.047 \mathrm{~m}^{3} \mathrm{H}_{2} \mathrm{~kg}^{-1} \mathrm{VS}, \mathrm{H}_{2} 30 \%\right)$. Similar loadings were then tested in a two-phase system. Hydraulic retention times of 3 and 12 days were applied to the first and second reactor respectively. In order to keep the $\mathrm{pH}$ at $\sim 5.5$, either supernatant or whole digestate from the methanogenic reactor was recirculated to the first phase. Results showed that hydrogen was produced $\left(0.117 \mathrm{Nm}^{3} \mathrm{~kg}^{-1} \mathrm{VS}, 47.7 \%\right)$ when recirculating whole digestate with an organic loading rate of $20 \mathrm{~kg} \mathrm{TVS} \mathrm{m}^{-3}$ day $^{-1}$.
\end{abstract}

Keywords: Biohydrogen, Biohythane, Two-phase, $\mathrm{pH}$ control, Anaerobic Digestion

*Corresponding author: Cristina Cavinato, cavinato@unive.it, phone +390422 321037, fax +39 0422326498. 


\section{Abbreviation}

AD: anaerobic digestion, FW: food waste, HRT: hydraulic retention time, SHP: specific hydrogen production, BHO: bio-hydrogen production, OLR: organic loading rate, PTOT: total phosphorus, SGP: specific gas production, SSC: steady state condition, TKN: total Kjeldahl nitrogen, TS: total solids, TVS: total volatile solids, VFAs: volatile fatty acids, IOL: initial organic loads, CSTR: continuous stirred tank reactor, GC: gas chromatography, OFMSW: organic fraction of municipal solid waste.

\section{Introduction}

Anaerobic digestion (AD) is a strong and well-established technique for renewable energy production. When applied to waste management, in addition to the production of carbon-neutral energy, it gives the extra benefit of treating organic wastes that would otherwise have to be processed in another way. The technique is even more attractive as it has also been demonstrated to be capable of producing hydrogen: this is already considered an important carrier for nextgeneration technologies, and much research is now focused on the best way to produce it in a clean and cost-effective way. Biological hydrogen production from organic biomass fermentation is widely considered as one of the best options with the greatest future potential [1]. Hydrogen is produced during fermentation and acetogenesis in the anaerobic digestion process, and a two-phase AD system can be exploited to produce both hydrogen and methane $[2,3]$. With such a scenario, the hydrogen could be used either by itself or to improve the combustion performance of methane, making a mixture that simulates the composition of Hythane. Such a mixture, often described as BioHythane, has a typical composition of $5-10 \% \mathrm{H}_{2}, 30-40 \% \mathrm{CO}_{2}, 50-65 \% \mathrm{CH}_{4}$, and has been shown to give better efficiency and emissions performance than natural gas when used in a conventional internal combustion engine $[4,5,6]$.

One of the most important challenges for sustaining hydrogen production in a reactor optimised for dark fermentation is to avoid the growth of $\mathrm{H}_{2}$-consuming bacteria [7]. Due to the daily addition of mixed culture contained in food waste (FW), there is always a risk that unwanted archaea such as $\mathrm{H}_{2}$-consuming methanogens could grow and deplete the hydrogen produced. There are many ways to select $\mathrm{H}_{2}$-producing bacteria in a mixed culture approach, such as physical-chemical treatment (heat-shock or chemical treatment of inoculum or substrate) or process parameter optimisation (low retention time, selection of organic loading). Many of these have already been discussed by other authors [8, 9, 10, 11]. 
Several reviews have been published on optimisation of conditions for biohydrogen production though dark fermentation, but there is still some confusion due to the wide range of conditions applied $[12,13]$. The type of substrate makes a big difference in terms of yield, and most studies have used simple synthetic substrates (e.g. glucose) that only require a short hydraulic retention time (HRT) in a single-stage reactor for effective conversion. FW is a combination of components some of which require more complex metabolic pathways to break them down. This affects the HRT, which typically ranges from 2 to 5 days in a continuous or semi-continuous fed system. Twophase approaches using FW as substrate without recirculation have been tested over a wide range of organic loadings $[14,15,16,17,18,19]$, and in general showed a specific hydrogen production (SHP) below $71 \mathrm{~m}^{3} \mathrm{H}_{2} \mathrm{~kg}^{-1}$ VS. Only a few studies have used a two phase approach with recirculation of the AD effluent $[11,14,16,20]$.

The present research used a two-phased approach with the objective of maximising hydrogen production in the first phase, while maintaining an acceptable methane conversion in the second phase. The purpose was to determine the best conditions for producing hydrogen in such a system using FW as substrate. The particular emphasis of the work was to develop a self-sustaining process that could be scaled up, using digestate recirculation as a means of controlling $\mathrm{pH}$ without external chemical additions. First, preliminary batch tests were carried out to test inoculum activity and determine the initial organic loading for a semi-continuous study. This type of test could be described as a Biohydrogen Production (BHP) test, since the reactors were fed only once at the start of the test and gas production and composition were monitored until no net production was achieved. In the semi-continuous experiments, four organic loading rates (OLR) were tested with recirculation of either whole digestate from the second phase or liquid obtained after centrifugation of the digestate, to determine which was most effective for $\mathrm{pH}$ control.

\section{MATERIALS AND METHODS}

\subsection{Substrate and inoculum characteristics}

The substrate used was source segregated domestic food waste collected from the South Shropshire Biowaste Digester in Ludlow, UK [21]. The material was first taken out of biodegradable plastic bags and any non-biodegradable contaminants (including large bones and fruit stones) were removed. It was then homogenised using a macerating grinder (S52/010 Waste Disposer, IMC Ltd, UK), packed into 4-litre plastic storage containers, and frozen at $-18{ }^{\circ} \mathrm{C}$. Before use the feedstock was thawed and stored at $4{ }^{\circ} \mathrm{C}$. The inoculum used was from Millbrook Wastewater Treatment Works, 
Southampton, UK, an anaerobic digestion plant treating municipal wastewater biosolids at an operating temperature of $37^{\circ} \mathrm{C}$. Table 1 presents the substrate and inoculum characteristics.

\section{Table 1.}

\subsection{Reactor configuration}

The continuously-stirred tank reactors (CSTR) used in this experimentation had volumes of either 2 or $5 \mathrm{~L}$ and were fitted with a flanged top plate through which a stirrer was inserted via a draught tube: this allowed the digester contents to be stirred continuously at $30 \mathrm{rpm}$ by an off-set bar stirrer, as shown in Figure 1. The digesters were maintained at $52{ }^{\circ} \mathrm{C}$ by circulation of hot water from a thermostatically controlled reservoir. Feeding was carried out via a hole in the top flange and digestate was removed via a wide-bore tube in the base. Gas production was measured with a gas flow meter (gas counter) constructed and calibrated as described by Walker and co-workers [22] and connected to gas sampling bags (SKC Ltd, Blandford Forum, UK). The device works by means of an inverted tipping bucket immersed in liquid. As the gas bubbles fill the bucket it tips and a magnet activates a reed switch connected to a counting device. Gas production is reported at STP of $0{ }^{\circ} \mathrm{C}$ and $101.325 \mathrm{kPa}$.

\section{Figure 1.}

\subsection{Analytical methods}

Total solids (TS), total volatile solids (TVS), total Kjeldahl nitrogen (TKN), chemical oxygen demand (COD) and ammonia were measured according to Standard Methods 2540 G, 4500 PJ, $5220 \mathrm{~B}$, and 4500- $\mathrm{NH}_{3} \mathrm{G}$, respectively [23]. $\mathrm{pH}$ was measured using a Jenway $3010 \mathrm{pH}$ meter (Jenway, London, UK) with temperature compensation and combination electrodes, calibrated daily with standard buffer solutions (Fisher Scientific UK Ltd, Loughborough, UK). Alkalinity was determined by titration with $0.25 \mathrm{~N} \mathrm{H}_{2} \mathrm{SO}_{4}$ to endpoint $\mathrm{pH} 4.0$ and the results expressed as total alkalinity. VFA concentrations were quantified in a Shimazdu GC-2010 gas chromatograph (Shimadzu, Milton Keynes, UK), using a flame ionisation detector and a capillary column type SGE BP-21 with helium as carrier gas. The GC oven temperature was programmed to increase from 60 to $210{ }^{\circ} \mathrm{C}$ in $15 \mathrm{~min}$, with a final hold time of $5 \mathrm{~min}$. The temperatures of injector and detector were 200 and $250{ }^{\circ} \mathrm{C}$, respectively. Standard solutions containing 50, 250 and $500 \mathrm{mg} / \mathrm{L}$ of acetic, propionic, iso-butyric, n-butyric, iso-valeric, valeric, hexanoic and heptanoic acids were used for VFA calibration. Samples for VFA determination were acidified by addition of formic acid to give a $10 \%$ concentration. Gas composition was measured using a Varian CP 3800 gas chromatograph 
(Varian, UK) with a gas sampling loop using argon as the carrier gas at a flow of $50 \mathrm{ml} \mathrm{min}^{-1}$. The GC was fitted with a Hayesep C column and a molecular sieve 13 x (80-100 mesh) operating at a temperature of $50{ }^{\circ} \mathrm{C}$. The $\mathrm{GC}$ was calibrated using standard gases containing $35 \% \mathrm{CO}_{2}$ and $65 \%$ $\mathrm{CH}_{4}$, and $20 \% \mathrm{H}_{2}$ with $80 \% \mathrm{~N}_{2}$.

\subsection{Experimental set-up}

For the batch tests, 12 reactors with a $2 \mathrm{~L}$ volume were initially filled in with $1.5 \mathrm{~L}$ of inoculum without any nutrient supplement, and held at $52{ }^{\circ} \mathrm{C}$ for 5 days. Tests were carried out in triplicate at initial organic loads (IOL) of 15, 20, 25, and $30 \mathrm{~kg} \mathrm{TVS} \mathrm{m}^{-3}$ corresponding to wet weight feed additions of 94.1, 138.2, 156.9 and $207.4 \mathrm{~g}$ of FW. The surplus of inoculum was hence removed in order to keep a total volume of $1.5 \mathrm{~L}$; substrate/inoculum TVS ratio was respectively $0.68,1.04$, 1.19 and 1.64. Gas production, gas composition and VFA concentration were measured every hour for the first 8 hours, then at longer intervals.

The semi-continuous trial was carried out in eight pairs of CSTR digesters, each pair comprising a hydrolytic reactor with a working volume of $1 \mathrm{~L}$, and a methanogenic digester with a working volume of $4 \mathrm{~L}$. Feeding of the reactors was carried out as shown in Table 2. Four pairs of reactors were operated with recirculation of whole digestate, and four with recirculation of digestate supernatant after centrifugation. To achieve this, $333 \mathrm{~mL}$ of digestate was removed every day from each phase before feeding. For the four systems with supernatant-only recirculation, the digestate from the methanogenic reactor was centrifuged at $3000 \mathrm{rpm}$ for 30 minutes in a refrigerated centrifuge (Centra-8R Model 2478, IEC Co., USA) and the supernatant was separated from the solids which were then disposed of. The amount of FW required in each case to give the desired OLR was then made up to $333 \mathrm{~mL}$ by adding either whole digestate or supernatant from the second phase, and the mixture was fed to the hydrolytic reactor. The digestate removed from the hydrolytic reactor was fed to the second phase. This gave internal HRT of 3 and 12 days in the hydrolytic and methanogenic reactors respectively, but the total HRT of the system was much longer (Table 2).

Gas production was monitored daily; gas composition, VFA and pH every two days; ammonia and alkalinity every three days; TS, TVS, COD, TKN once per week.

\section{Table 2.}

\section{Results and discussion}

\subsection{Batch tests}


The results of the batch tests (Table 3) showed that increasing the initial organic load led to a progressive increase in hydrogen production, with IOL of 15, 20, 25 and $30 \mathrm{~kg} \mathrm{TVS} \mathrm{m}^{-3}$ giving SHP of $0.012,0.021,0.035$ and $0.047 \mathrm{Nm}^{3} \mathrm{~kg}^{-1}$ TVS respectively. These values were reached after $24 \mathrm{~h}$ in fact the maximum hydrogen content was reached before $24 \mathrm{~h}$ in all tests. In contrast the specific biogas production decreased with increasing IOL from 0.782 at IOL 15 to $0.239 \mathrm{Nm}^{3} \mathrm{~kg}^{-1} \mathrm{TVS}_{\text {at }}$ IOL 30. The methane content also fell, and at $30 \mathrm{~kg} \mathrm{TVS} \mathrm{m}^{-3}$ only accounted for about $10 \%$ of the gas volume. In terms of cumulative yield, the highest hydrogen production was at $30 \mathrm{~kg} \mathrm{TVS} \mathrm{m}^{-3}$ (2116 $\mathrm{mL}$ of $\mathrm{H}_{2}$ in 327 hours); methane and total biogas production were both maximised at $25 \mathrm{~kg}$ TVS m${ }^{-3}$ with $12.58 \mathrm{~L}$ of $\mathrm{CH}_{4}$ and $24.80 \mathrm{~L}$ of biogas in 327 hours.

Table 3.

\section{Table 4.}

As shown in Table 4, the results obtained in the present research are very close to those of Jinming and co-workers [24], who carried out batch tests on a similar type of FW without any pre-treatment or $\mathrm{pH}$ control, and found SHP of 0.057 and $0.039 \mathrm{Nm}^{3} \mathrm{~kg}^{-1} \mathrm{TVS}$ in the thermophilic and mesophilic ranges respectively. The batch tests in this research demonstrated that in a single reactor dark fermentation can be isolated by applying an IOL of $30 \mathrm{~kg} \mathrm{TVS} \mathrm{m}^{-3}$ or above, as at this load methanogenesis was completely inhibited while hydrogen production was constant and continuous with an average $\mathrm{H}_{2}$ concentration of $6.4 \%$ throughout the 327 hours of the test (Table 3). These results confirmed that high organic loadings enhance hydrogen production whilst as the same time inhibiting methanogenesis, probably as a result of the accumulation of intermediate products leading to a fall in $\mathrm{pH}$. Figures $2 \mathrm{a}$ and $2 \mathrm{~b}$ show the profiles of total VFA and some individual acids

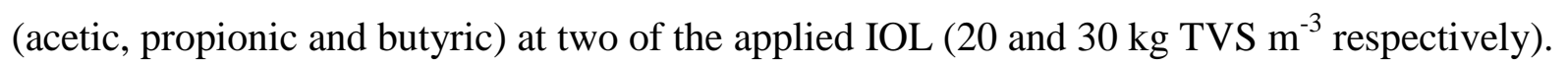

\section{Figure 2.}

At IOL 20 there was an accumulation of acetic and butyric acids during the first $150 \mathrm{~h}$, almost all of which was then converted into methane and carbon dioxide after $300 \mathrm{~h}$. This showed that methanogenic activity was not inhibited and the microorganisms were able to use and convert the VFA into $\mathrm{CH}_{4}$ and $\mathrm{CO}_{2}$. In contrast, IOL 30 showed accumulation of VFA with no subsequent conversion to methane, indicating that methanogenesis was inhibited; this condition gave the best hydrogen yields compared to the other IOL tested. 


\subsection{Semi-continuous trials}

The trials carried out with supernatant recirculation showed no positive results in term of hydrogen production. At the higher OLRs of 25 and $30 \mathrm{~kg} \mathrm{TVS} \mathrm{m}^{-3}$ day $^{-1}$, the first phase immediately fell into acidic conditions, leading quickly to failure in the methanogenic phase. The two lower OLRs of 15 and $20 \mathrm{~kg}$ TVS m${ }^{-3}$ day $^{-1}$ showed the ability to sustain methanogenesis in the second phase. In the conditions applied, however, the $\mathrm{pH}$ in the first phase was always below 4.5, far from the optimal range for hydrogenase enzyme of 5.5-6.5 [25]. The conditions at OLR of 15 and $20 \mathrm{~kg} \mathrm{TVS} \mathrm{m}^{-3}$ day $^{-}$

${ }^{1}$ instead gave a good example of two-phase AD for methane production, where the first phase provides optimal conditions for hydrolysis and the second phase for methanogenesis. The OLR of $20 \mathrm{~kg} \mathrm{TVS} \mathrm{m}^{-3}$ day $^{-1}$ in particular could be considered as an optimal loading for a two-phase system, as it gave the highest SGP of over above $0.8 \mathrm{Nm}^{3} \mathrm{~kg}^{-1} \mathrm{VS}$, although steady state conditions had not yet been reached.

The tests carried out with recirculation of the whole digestate gave much more interesting results. Table 5 summarises all of the parameters monitored for all four reactor pairs, together with the yield from the process. As can be seen, the loading of $20 \mathrm{~kg} \mathrm{TVS} \mathrm{m}^{-3} \mathrm{day}^{-1}$ on the hydrolytic reactor gave the best performance with a stable hydrogen concentration of $47.7 \%$ in the first phase (Figure $3 \mathrm{a}$ ) and $60 \%$ methane in the second phase (Figure $3 b$ ).

\section{Table 5.}

\section{Figure 3.}

In Figure $3 \mathrm{c}$ it can be seen that the SGP with a loading of $20 \mathrm{~kg} \mathrm{TVS} \mathrm{m}^{-3} \mathrm{day}^{-1}$ on the first phase showed a small decrease after day 32 for several days, but then regained a stable value of around $0.240 \mathrm{Nm}^{3} \mathrm{~kg}^{-1}$ TVS. The SHP (Figure 3d) showed a similar trend, with an average production of $0.117 \mathrm{Nm}^{3} \mathrm{~kg}^{-1}$ TVS. $\mathrm{pH}$ and total alkalinity in first phase were stable at 5.22 and $8.5 \mathrm{~g} \mathrm{CaCO}_{3} \mathrm{~L}^{-1}$ respectively after day 15 . Total VFA in the first phase was quite high as expected, stabilising at around $13.8 \mathrm{~g} \mathrm{COD} \mathrm{L}^{-1}$, but with no signs of further accumulation. Ammonia on the other hand showed an upward trend, reaching around $2.7 \mathrm{~g} \mathrm{NH}_{4}{ }^{+}-\mathrm{N} \mathrm{L}^{-1}$ in the final week.

Table 6 shows results from other studies in which hydrogen has been produced under similar conditions and where external $\mathrm{pH}$ control was not used. The $\mathrm{H}_{2}$ concentration and SHP found in the present work are far higher than that measured by other authors; a better performance is reported only by Chu and co-workers [16], who found an SHP of $0.205 \mathrm{Nm}^{3} \mathrm{~kg}^{-1}$ TVS with an $\mathrm{H}_{2}$ concentration of $52-56 \%$. 


\section{Table 6.}

At the loading of $20 \mathrm{~kg}$ TVS m $\mathrm{m}^{-3} \mathrm{day}^{-1}$ on the hydrolytic reactor, a stable methane concentration of $61.2 \%$ was established in the second phase after about 15 days (Figure 3c) and the SGP was 0.512 $\mathrm{Nm}^{3} \mathrm{~kg}^{-1}$ VS. $\mathrm{pH}$ was stable at 7.69 throughout the trial. With respect to VFA, acetic and butyric acids were detected at fairly low and stable concentrations throughout the experimental run, while propionic acid accumulated sharply during the first 15 days. Total VFA were still accumulating slightly at the end of the run, with an average value in the final two weeks of $7.1 \mathrm{~g} \mathrm{COD} \mathrm{L}^{-1}$. Ammonia also accumulated, with the average for the last week equal to $3.3 \mathrm{~g} \mathrm{NH}_{4}{ }^{+}-\mathrm{N} \mathrm{L}^{-1}$. The total SGP for the whole two-phase system was $0.752 \mathrm{Nm}^{3} \mathrm{~kg}^{-1} \mathrm{TVS}$.

Two phase approaches with conditions similar to those applied in this experiment have been tested by others, as shown in Table 7. The performance of the second phase was similar in terms of SGP to that in the present study.

\section{Table 7.}

Concerning the other three load conditions, some observations can be made based on the results in Table 5. The loading of $15 \mathrm{~kg} \mathrm{TVS} \mathrm{m}^{-3} \mathrm{day}^{-1}$ on the hydrolytic reactor was insufficient to reduce the $\mathrm{pH}$ to the optimum of 5.5 for dark fermentation, so that on recirculation of whole digestate the $\mathrm{H}_{2}$ consuming and $\mathrm{CH}_{4}$-producing archaea were no longer inhibited, with consequent methane production. The loading of $25 \mathrm{~kg} \mathrm{TVS} \mathrm{m}^{-3}$ day $^{-1}$ on the hydrolytic reactor was too high for the system tested as the alkalinity recirculated was insufficient, resulting in a reduction of $\mathrm{pH}$ to the point where hydrogen production was not possible in the first phase. As happened with supernatant recirculation, the system behaved like a two-phase system for methane production. As result, in the first phase only solubilisation of organic compounds occurred, while in the second phase methanogenesis showed good performance as the COD arrived already solubilised and ready to use. The results obtained during the working period at $30 \mathrm{~kg} \mathrm{TVS} \mathrm{m}^{-3} \mathrm{day}^{-1}$ showed that raising the organic load gave a general inhibition of both the phases. The SHP, SMP and SGP are shown in Figure 4.

\section{Figure 4.}


The results clearly showed that not all of the conditions tested were suitable for combined hydrogen and methane production. At all of the loadings tested, recirculation of supernatant alone from the second phase did not lead to adequate $\mathrm{pH}$ control and was not sufficient to sustain dark fermentation for hydrogen production in the first phase. Recirculation of whole digestate returned not only alkalinity but also biomass, providing a continual inoculum of fermentative organisms to the first phase. At the two lower loadings this also allowed the recycled methanogenic organisms to take advantage of the acids and hydrogen produced, preventing the necessary drop in $\mathrm{pH}$. At the highest loading where over-acidification occurred, it is possible that a greater volume of digestate could be recirculated from the second stage to improve the alkalinity in the first stage reactor. This would however reduce the internal HRT in both phases. It is clear that a suitable balance has to be achieved between OLR, total HRT and internal HRT in the two phases, and for this substrate the balance appears to be at a loading of around $20 \mathrm{~kg} \mathrm{TVS} \mathrm{m}^{-3} \mathrm{day}^{-1}$ on the hydrolytic reactor, corresponding to an OLR on the whole system of $4 \mathrm{~kg} \mathrm{TVS} \mathrm{m}^{-3}$ day $^{-1}$. This loading rate gave a final gas composition of $18 \% \mathrm{H}_{2}, 39 \% \mathrm{CH}_{4}$ and $43 \% \mathrm{CO}_{2}$ which does not match the ideal biohythane profile as the percentage of hydrogen is too high. There are a number of possible solutions for this, such as splitting the food waste load so that a proportion is added directly to the second phase reactor; or alternatively dosing some of the hydrogen-rich gas from the first into the second phase reactor as a substrate for hydrogentrophic methanogenesis. The main problem seen in the operation of this system was the accumulation of ammonia: this in turn may be associated with population changes in the anaerobic consortium and with VFA accumulation [26, 27]. This is likely to lead to deterioration in system performance, although it is unclear whether this would first affect the hydrolytic or methanogenic phase. Although trace element addition has been shown to prevent propionic acid accumulation in mesophilic FW digestion [28] this solution has so far not proved effective in thermophilic conditions with the same food waste [29]. For future scale-up of the process, measures to control ammonia accumulation may have to be applied: an example of a possible solution is given by Cavinato and co-workers [30].

\section{Conclusions}

Batch tests were effective in showing the suitability of the selected inoculum/substrate ratios for testing for hydrogen production in the thermophilic range. During batch tests, the highest initial load gave the greatest hydrogen yield, while methanogenesis was completely inhibited at an IOL of $30 \mathrm{~kg} \mathrm{TVS} \mathrm{m}^{-3}$. 
Semi-continuous trials with supernatant recirculation did not show any significant hydrogen production. The supernatant recirculated about $90 \%$ of the digestate alkalinity but this was not enough to control the $\mathrm{pH}$ in the first phase, where acidic conditions established within the first week. At OLR of 25 and $30 \mathrm{~kg} \mathrm{TVS} \mathrm{m}^{-3}$ day $^{-1}$ on the hydrolytic reactor both phases were completely inhibited, while at 15 and $20 \mathrm{~kg} \mathrm{TVS} \mathrm{m}^{-3}$ day $^{-1}$ the system acted as a two-stage AD system for methane production.

Tests with whole digestate recirculation demonstrated that a high hydrogen yield could be achieved with an OLR of $20 \mathrm{~kg} \mathrm{TVS} \mathrm{m}^{-3} \mathrm{day}^{-1}$ on the hydrolytic reactor. With the recirculation conditions applied, the load of $15 \mathrm{~kg} \mathrm{TVS} \mathrm{m}^{-3}$ day $^{-1}$ was too low and led to a methanogenic shift within the first month, while 25 and $30 \mathrm{~kg}^{\mathrm{TVS} \mathrm{m}} \mathrm{m}^{-3}$ day $^{-1}$ were too high and led to acidic conditions in the first phase.

For hydrogen production the best yield was obtained at an OLR of $20 \mathrm{~kg} \mathrm{TVS} \mathrm{m}^{-3} \mathrm{day}^{-1}$ on the hydrolytic reactor and recirculating whole digestate with a Qr/Qin ratio of 2.9. In the first phase $\mathrm{pH}$ was self-controlled over the experimental period at a value of 5.22 and a SHP of $0.117 \mathrm{Nm}^{3} \mathrm{~kg}^{-1} \mathrm{VS}$ was observed. Hydrogen concentration in the biogas was $47.7 \%$. SGP in the second phase was $0.512 \mathrm{Nm}^{3} \mathrm{~kg}^{-1} \mathrm{VS}$ while the total SGP was $0.752 \mathrm{Nm}^{3} \mathrm{~kg}^{-1} \mathrm{VS}$. These results are better than achieved in most previous studies, but there are issues in relation to long term stability as a result of high ammonia concentrations, possibly associated with volatile fatty acid accumulation. If a solution to this can be found the process appears promising for scale-up.

\section{Acknowledgments}

This work was carried out with the support of the EU FP7 VALORGAS Project (ENERGY.2009.3.2.2, grant 241334).

\section{References}

[1] Kotay S. M., Das D. Biohydrogen as a renewable energy resource-Prospects and potentials. International Journal of Hydrogen Energy. (2008), 33, 258-263

[2] Kapdan I. K., Kargi F. Bio-hydrogen production from waste materials. Enzyme and Microbial Technology. (2006), 38, 569-582

[3] Hallenbeck P.C., Ghosh D. Improvements in fermentative biological hydrogen production through metabolic engineering. Journal of Environmental Management, (2012) 95, S360-S36 
[4] Porpatham E., Ramesh A., Nagalingam B. Effect of hydrogen addition on the performance of a biogas fuelled spark ignition engine. International Journal of Hydrogen Energy. (2007), 32, 2057-2065

[5] Martınez-Perez N., Cherryman S.J., Premier G.C., Dinsdale R.M., Hawkes D.L., Hawkes F.R., Kyazze G., Guwy A.J. The potential for hydrogen-enriched biogas production from crops: Scenarios in the UK. Biomass and Bioenergy, (2007). 31, 95-104

[6] Rakopoulos C. D., Michos C. N. Generation of combustion irreversibilities in a spark ignition engine under biogas-hydrogen mixtures fueling. International Journal of Hydrogen Energy. (2009), 34, 44224437

[7] Cooney M., Maynard N., Cannizzaro C., Benemann J. Two-phase anaerobic digestion for production of hydrogen-methane mixtures. Bioresource Technology, (2007) 98(14), 2641-2651.

[8] Kraemer T. J., Bagley D. M. Improving the yield from fermentative hydrogen production. Biotechnology Letters. (2007), 29, 685-695.

[9] Valdez-Vazquez I., Poggi-Varaldo H. M. Hydrogen production by fermentative consortia. Renewable and Sustainable Energy Reviews. (2009), 13, 1000-1013

[10] Liu H., Wang J., Wang A., Chen J. Chemical inhibitors of methanogenesis and putative applications. Applied Microbiology Biotechnology. (2011), 89, 1333-1340

[11] Cavinato C., Bolzonella D., Fatone F., Cecchi F., Pavan P. Optimization of two-phase thermophilic anaerobic digestion of biowaste for hydrogen and methane production through reject water recirculation. Bioresources technology, special issue on Biofuels, (2011), 102 8605-8611.

[12] Wang, J. and Wan, W. Experimental design methods for fermentative hydrogen production: A review. International Journal of Hydrogen Energy, (2009), 34(1), 235-244.

[13] Wang, J. and Wan, W. Factors influencing fermentative hydrogen production: A review. International Journal of Hydrogen Energy (2009), 34(2), 799-811.

[14] Kataoka N., Ayame S., Miya A., Ueno Y., Oshita N., Tsukahara K., Sawayama S., Yokota N. (2005). Studies on hydrogen-methane fermentation process for treating garbage and waste paper. ADSW 2005 Conference Proceedings, 2, Process Engineering

[15] Liu D., Liu D., Zeng R.J., Angelidaki I. Hydrogen and methane production from household solid waste in the two stage fermentation process. Water Research. (2006), 40, 2230-2236

[16] Chu C.F., Li Y.Y., Xu K.Q., Ebie Y., Inamori Y., Kong H.N. A pH- and temperature-phased two-stage process for hydrogen and methane production from food waste. International Journal of Hydrogen Energy. 33 (2008), 4739-4746

[17] Wang X., Zhao Y.C. A bench scale study of fermentative hydrogen and methane production from food waste in integrated two-stage process. International journal of hydrogen energy, (2009), 43, 245-254.

[18] Koutrouli E.C., Kalfas H., Gavala H.N., Skiadas I.V., Stamatelatou K., Lyberatos G. Hydrogen and methane production through two-stage mesophilic anaerobic digestion of olive pulp. Bioresource Technology. (2009), 100, 3718-3723 
[19] Luo G., Xie L., Zhou Q., Angelidaki I. Enhancement of bioenergy production from organic wastes by two-stage anaerobic hydrogen and methane production process. Bioresource Technology, (2011), 102(18), 8700-8706.

[20] Lee D.Y., Ebie Y., Xu K.Q., Li Y.Y., Inamori Y. Continuous H2 and CH4 production from high-solid food waste in the two-stage thermophilic fermentation process with the recirculation of digester sludge. Bioresource Technology. (2010), 101, 542-547

[21] Banks C. J, Chesshire M., Heaven S., Arnold R. Anaerobic digestion of source-segregated domestic food waste: Performance assessment by mass and energy balance. Bioresource Technology, (2011), 102(2), 612-620.

[22] Walker M., Zhang Y., Heaven S., Banks C.J. Potential errors in the quantitative evaluation of biogas production in anaerobic digestion processes Bioresource Technology. (2009), 100 (24), 6339-6346

[23] APHA, Standard Methods for the Examination of Water and Wastewater, 21st ed. American Public Health Association, American Water Works Association, Water Environment Federation, Washington, DC, USA (2005).

[24] Jinming P., Ruihong Z., Hamed M., Huawei S., Yibin Y. Effect of food to microorganism ratio on biohydrogen production from food waste via anaerobic fermentation. International Journal of Hydrogen Energy,.(2008) 33(23), 6968-6975.

[25] Guo X. M., Trably E., Latrille E., Carrere H., Steyer J.P. Hydrogen production from agricultural waste by dark fermentation: A review. International Journal of Hydrogen Energy (2010), 35(19), 10660-10673.

[26] Karakashev D., Batstone, D.J., Angelidaki, I. Influence of Environmental Conditions on Methanogenic Compositions in Anaerobic Biogas Reactors. Applied and Environmental Microbiology (2005), 71(1), 331-338.

[27] Speece R.E., Boonyakitsombut, S., Kim, M., Azbar, N. and Ursillo, P. Overview of anaerobic treatment: Thermophilic and propionate implications. Water Environment Research (2006), 78(5), 460-473.

[28] Banks C.J., Zhang Y., Jiang Y. and Heaven S. Trace element requirements for stable food waste digestion at elevated ammonia concentrations. Bioresource Technology (2012), 104(0), 127-135.

[29] Yirong I. C., Banks C. J., Heaven S. Volatile fatty acid accumulation in thermophilic anaerobic digestion of food waste. 6th IWA International Symposium on Anaerobic Digestion of Solid Waste and Energy Crops. 28 August - 1 September 2011, Wien.

[30] Cavinato C., Giuliano A., Bolzonella D., Pavan P., Cecchi F. Bio-hythane production from food waste by dark fermentation coupled with anaerobic digestion process: A long-term pilot scale experience. International Journal of Hydrogen Energy, (2012), 37, 11549-11555.

[31] Elbeshbishy E., Hafez H., Dhar B.R., Nakhla G. Single and combined effect of various pretreatment methods for biohydrogen production from food waste. International Journal of Hydrogen Energy, (2011). 36, (17) 11379-11387.

[32] Kim S.H., Han S.K., Shin H.S. Feasibility of biohydrogen production by anaerobic co-digestion of food waste and sewage sludge. International Journal of Hydrogen Energy. (2004), 29, 1607-1616 
[33] Zhu H., Parker W, Basnar B., Propacki A., Falletta P., Beland M., Seto P. Biohydrogen production by anaerobic co-digestion of municipal food waste and sewage sludges. International Journal of Hydrogen Energy. (2008), 33, 3651-3659

[34] Liu D., Min B., Angelidaki I. Biohydrogen production from household solid waste (HSW) at extremethermophilic temperature (70 8C) - Influence of $\mathrm{pH}$ and acetate concentration. International Journal of Hydrogen Energy. (2008), 33, 6985-6992

[35] Okamoto M., Miyahara T., Mizuno O., Noike T. Biological hydrogen potential of materials characteristic of the organic fraction of municipal solid wastes. Water Science and Technology. (2000), $41(3), 25-32$

[36] Valdez-Vazquez I., Rios-Leal E., Esparza-Garcia F., Cecchi F., Poggi-Varaldo H. M. Semi-continuous solid substrate anaerobic reactors for $\mathrm{H} 2$ production from organic waste: Mesophilic versus thermophilic regime. International Journal of Hydrogen Energy. (2005), 30, 1383-1391

[37] Banks C. J., Zotova E. A., Heaven S. Biphasic production of hydrogen and methane from waste lactose in cyclic-batch reactors. Journal of Cleaner Production. (2010), 18, S95-S104

[38] Lee Y.W., Chung J. Bioproduction of hydrogen from food waste by pilot-scale combined hydrogen/methane fermentation. International Journal of Hydrogen Energy. (2010), 35, 11746-11755

\section{Tables}

Table 1. Characteristics of substrate and inoculum

Table 2. Experimental conditions in semi-continuous trial

Table 3. Batch test results at four initial organic loadings

Table 4. Reference results for batch tests carried out using Food Waste as substrate

Table 5. Steady state condition average values of process parameters for loadings of 15, 20, 25 and $30 \mathrm{~kg} \mathrm{TVS} \mathrm{m}^{-3}$ day $^{-1}$ applied to the hydrolytic reactor of a two-phase system treating FW with digestate recirculation

Table 6. Experimental conditions and hydrogen yields in CSTR-type reactors treating FW only without external $\mathrm{pH}$ control

Table 7. Experimental condition applied and hydrogen yields without pre-treatment and external $\mathrm{pH}$ control in a two-phase system

\section{Figures}


Figure 1: Cross-section diagram of CSTR digesters showing heating coils (left) and stirrer (right) [37].

Figure 2: a) VFA production during IOL 20; b) VFA production during IOL 30.

Figure 3. Gas production parameters at OLR $20 \mathrm{~kg} \mathrm{TVS} \mathrm{m}^{-3}$ day $^{-1}$ with whole digestate recirculation: a) Gas composition of the first phase; b) Gas composition of the second phase; c) SGP; d) SHP and SMP

Figure 4. Specific gas productions for all loadings tested with whole digestate recirculation 
Figure 1

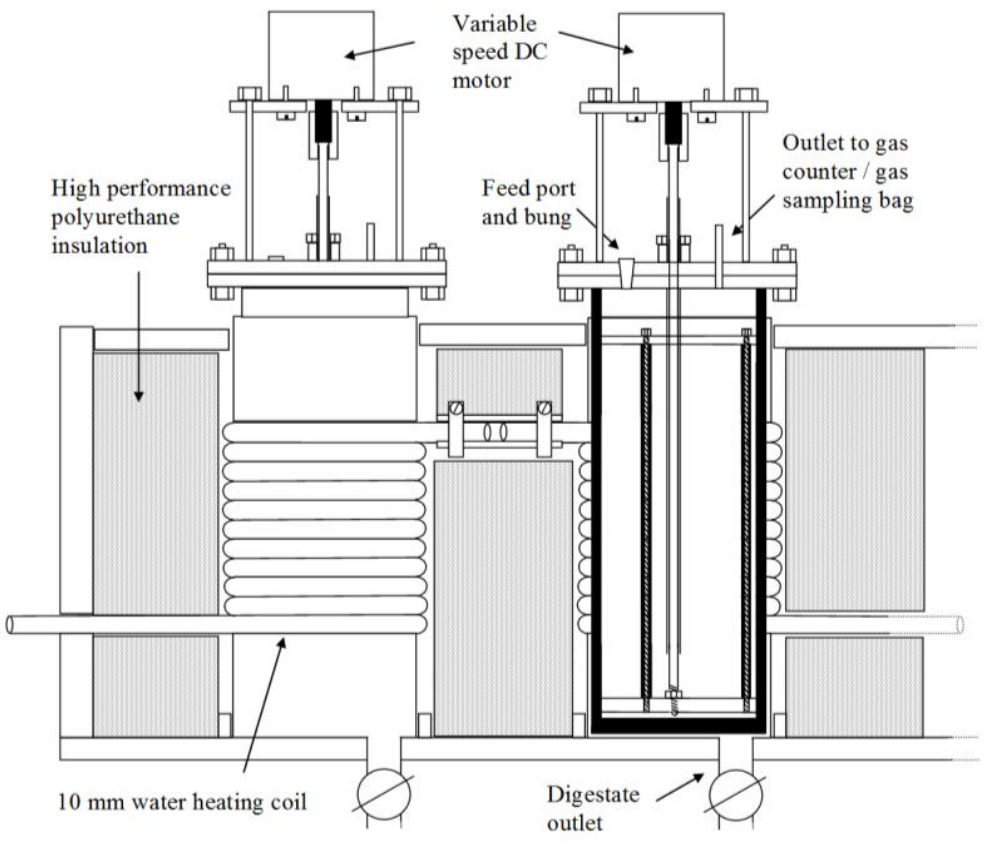

Figure 2
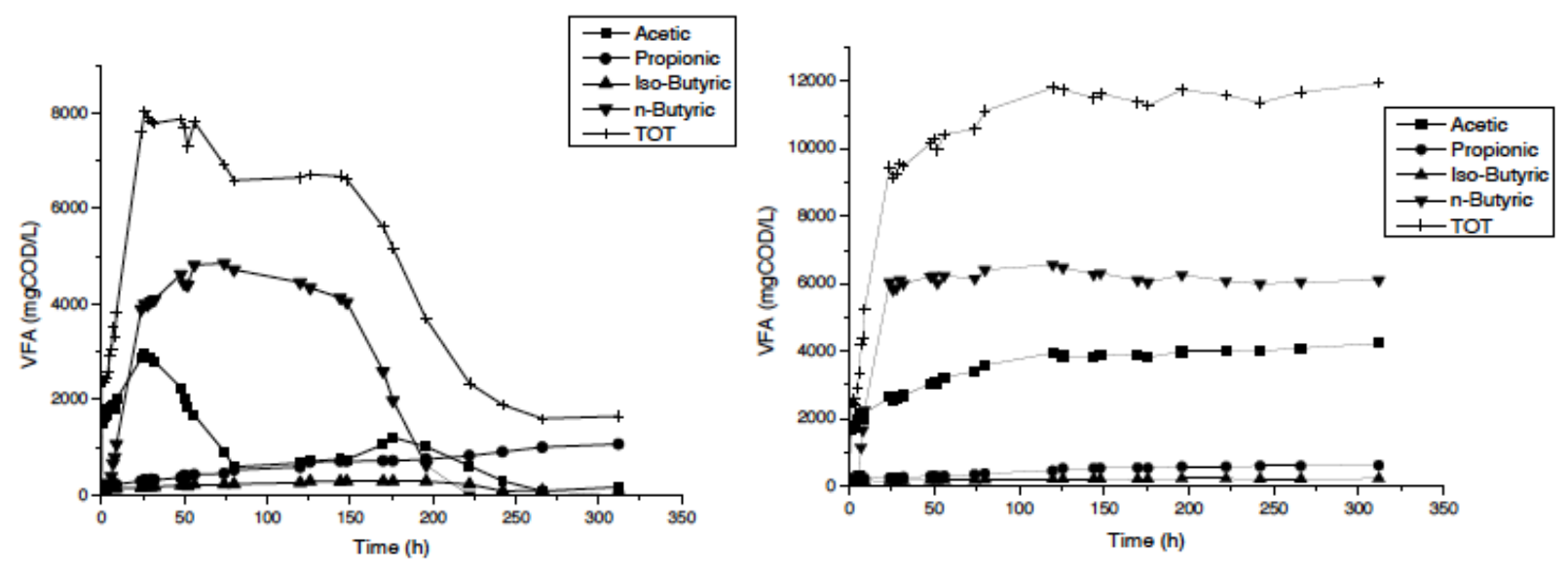

a)

b) 
Figure 3
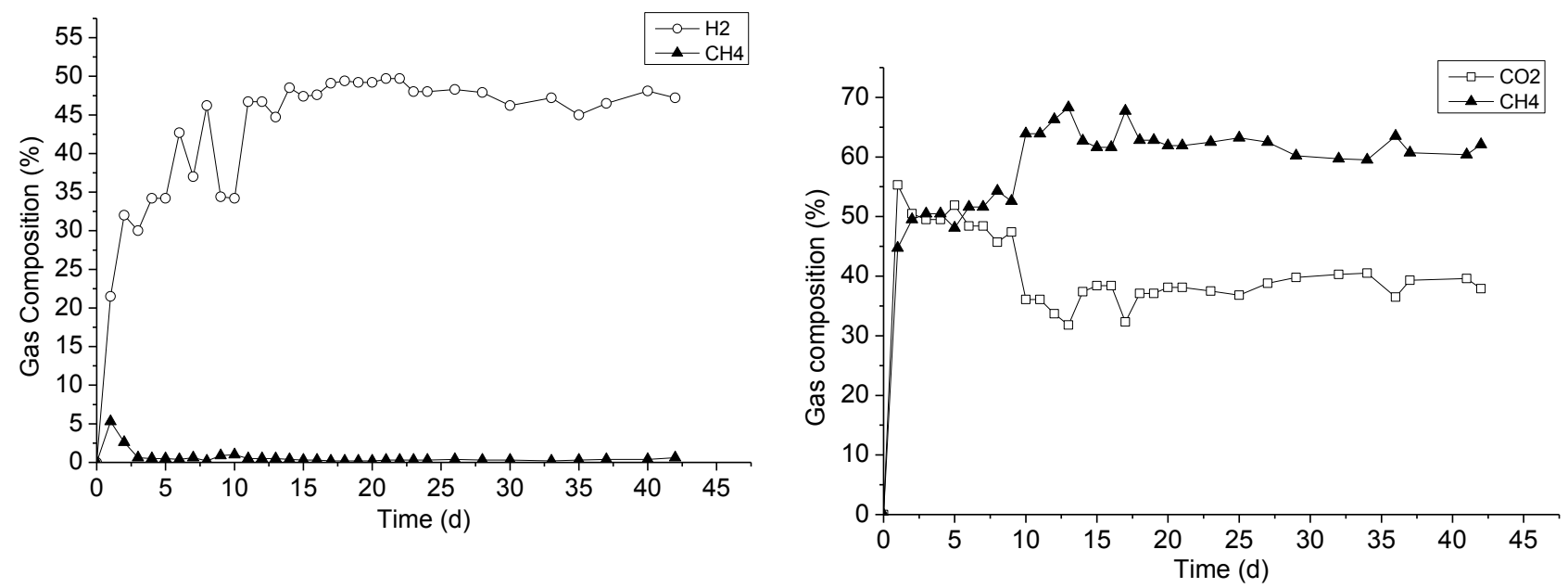

a)

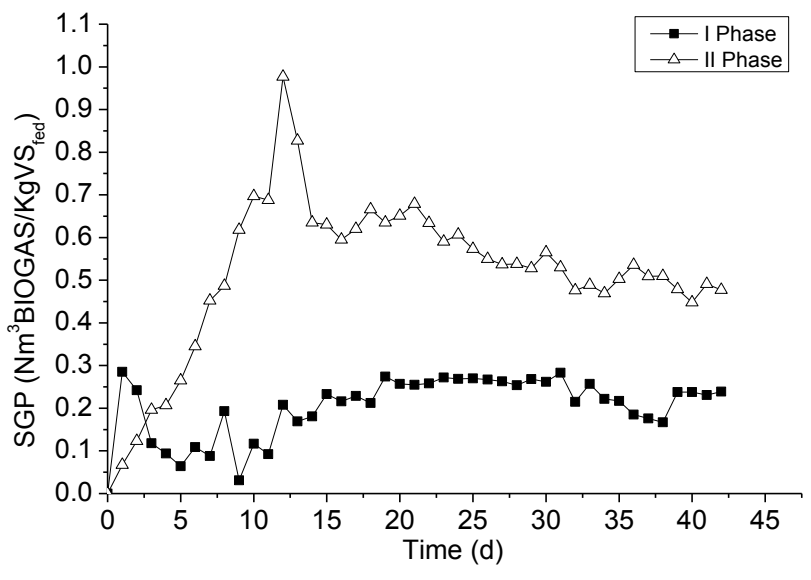

c

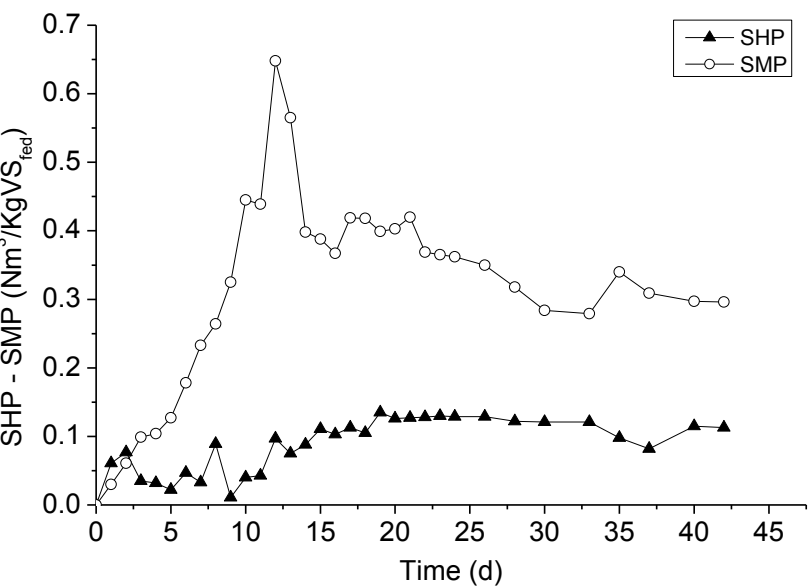

d) 
Figure 4

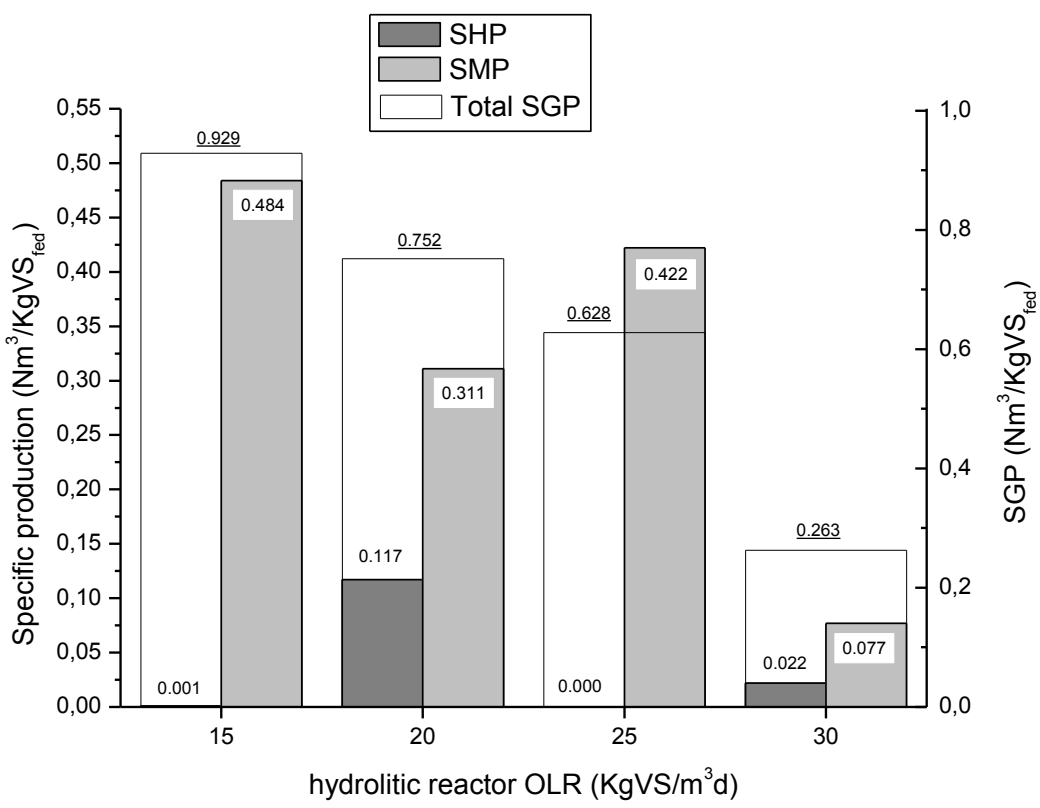

